American Journal of Applied Sciences 7 (5): 656-660, 2010

ISSN 1546-9239

(C) 2010Science Publications

\title{
New Schiff Bases with Pyridine Core: Spectral, Thermal and Optical Characterizations
}

\author{
${ }^{1}$ Sie-Tiong Ha, ${ }^{2}$ Lay-Khoon Ong, ${ }^{1}$ Yip-Foo Win, ${ }^{3}$ Guan-Yeow Yeap, \\ ${ }^{4}$ Nilesh L. Bonde and ${ }^{3}$ Peng-Lim Boey \\ ${ }^{1}$ Department of Chemical Science, Faculty of Science, Universiti Tunku Abdul Rahman, \\ Jln Universiti, Bandar Barat, 31900 Kampar, Perak, Malaysia \\ ${ }^{2}$ Department of Science, Faculty of Engineering and Science, Universiti Tunku Abdul Rahman, \\ Jln Genting Klang, Setapak, 53300 Kuala Lumpur, Malaysia \\ ${ }^{3}$ Liquid Crystal Research Laboratory, School of Chemical Science, \\ Universiti Sains Malaysia, 11800 Minden, Penang, Malaysia \\ ${ }^{4}$ Sterling Biotech Ltd., Jambusar State Highway, Village Masar, Tal: Padra, Dist. Vadodara, India
}

\begin{abstract}
Problem statement: Numerous studies have been conducted on the Schiff base's alkyl and alkyloxy possessing aromatic core. However, the thermo tropic properties of Schiff base's ester (or alkanoyloxy) with pyridine core was rare studied. Approach: To study spectral, thermal and optical behaviors of Schiff base ester possessing heterocyclic (pyridine) terminal core. A series of 4-[(pyridin3-ylmethylene) amino] phenylalkanoates were prepared and all the members are differed by the length of alkanoyloxy chain, $\mathrm{C}_{\mathrm{n}-1} \mathrm{H}_{2 \mathrm{n}-1} \mathrm{COO}$, where $\mathrm{n}=12,14,16$ and 18 . The thermal and optical characteristics were studied using differential scanning calorimetry and polarizing optical microscopy. Results: DSC studies showed that all of the title compounds exhibited direct isotropization and recrystallization during heating and cooling cycles, respectively. Under polarizing optical microscope, crystal phase texture was observed to change to dark region isotropic without displaying any liquid crystal phase. Conclusion: The presence of terminal pyridine core suppressed the formation of mesosphere in the compounds studied.
\end{abstract}

Key words: Pyridine, azomethine, thermo tropic, phase transition

\section{INTRODUCTION}

N-Benzylideneaniline Schiff bases having $\mathrm{C}_{6} \mathrm{H}_{5} \mathrm{CH}$ $=\mathrm{NC}_{6} \mathrm{H}_{5}$ system has received a considerable amount of attention from many researchers owing to its importance in exhibiting thermochromism and phototropism (Hadjoudis et al., 1987). A series of studies on photochromic compounds have been undertaken with an attempt to explore the applications of these photochromic materials in various fields such as the control and measurement of radiation intensity, optical computers and display systems. In view of the importance and usefulness of these compounds, chemists are prompted to generate the derivatives by introducing different substituents into the existing skeleton of the molecule. The presence of a long alkyl chain at the para position of the aldehyde and aniline fragments of Schiff bases has been regarded as one of the important elements which favor the existence of liquid crystal phases (Yeap et al., 2004; 2006a; 2006b; 2006c).
Subsequent to the concerted effort in studying Schiff bases, an attempt to study Schiff base esters consisting of a pyridine moiety was carried out by preparing a new series of 4-[(pyridin-3ylmethylene)amino] phenylalkanoate $\left(\mathrm{C}_{5} \mathrm{H}_{4} \mathrm{NCH}=\right.$ $\mathrm{NC}_{6} \mathrm{H}_{4} \mathrm{R}$, where $\mathrm{R}=\mathrm{C}_{11} \mathrm{H}_{23} \mathrm{COO}-, \mathrm{C}_{13} \mathrm{H}_{27} \mathrm{COO}-$, $\mathrm{C}_{15} \mathrm{H}_{31} \mathrm{COO}-$ and $\mathrm{C}_{17} \mathrm{H}_{35} \mathrm{COO}-$ ). The structures of the title compounds were confirmed using microelemental analysis and spectroscopic techniques (EIMS, FTIR and NMR). Differential scanning calorimetry and polarizing optical microscope were used to study phase behavior and optical textures of the title compounds.

\section{MATERIALS AND METHODS}

3-Pyridinecarbaldehyde, 4-aminophenol and 4Dimethylaminopyridine (DMAP) were obtained from Merck (Germany). Dicyclohexylcarbodiimide (DCC) was obtained from Acros Organics (USA).

Corresponding Author: Sie-Tiong Ha, Department of Chemical Science, Faculty of Science, Universiti Tunku Abdul Rahman, Jln Universiti, Bandar Barat, Kampar, 31900 Perak, Malaysia 
Am. J. Applied Sci., 7 (5): 656-660, 2010

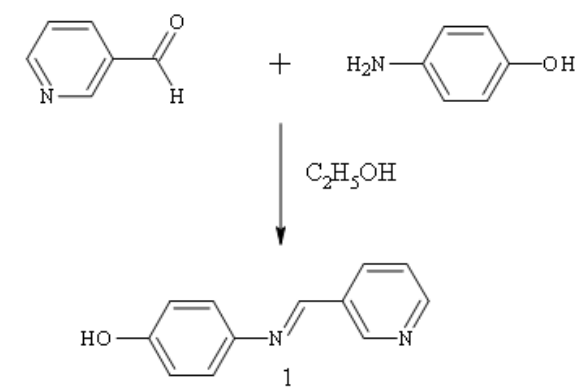

Table 1: Selected mass and infrared spectral data of Schiff bases 1-5

\begin{tabular}{|c|c|c|c|c|c|}
\hline \multirow[b]{2}{*}{$\begin{array}{l}\text { Schiff } \\
\text { base }\end{array}$} & \multicolumn{2}{|c|}{$\operatorname{MS}(\mathrm{m} / \mathrm{z})$} & \multicolumn{3}{|c|}{$\begin{array}{l}\text { IR wave number and band assignment } \\
\left(\mathrm{v}, \mathrm{cm}^{-1}\right)\end{array}$} \\
\hline & $\mathrm{M}^{+}$ & $\begin{array}{l}\text { Base } \\
\text { peak }\end{array}$ & $\mathrm{C}-\mathrm{H}$ & $\mathrm{C}=\mathrm{O}$ & $\mathrm{C}=\mathrm{N}$ \\
\hline 2 & 380 & 198 & $2953,2916,2849$ & 1755 & 1626 \\
\hline 3 & 408 & 198 & $2954,2916,2848$ & 1754 & 1626 \\
\hline 4 & 436 & 198 & $2954,2916,2848$ & 1754 & 1626 \\
\hline 5 & 464 & 198 & $2954,2916,2848$ & 1754 & 1626 \\
\hline
\end{tabular}

Table 2: ${ }^{1} \mathrm{H}$ NMR data of Schiff base 5

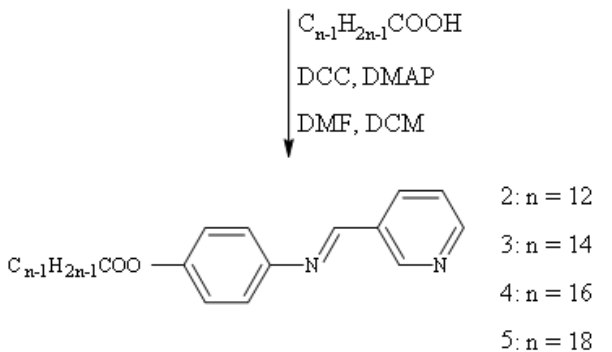

Scheme 1: Synthetic methodology for Schiff bases 2-5

Lauric, myristic, palmitic and stearic acids were supplied by Natural Oleochemicals Sdn. Bhd. (Malaysia). The purity of the fatty acids is approximately $99 \%$.

Techniques: Electron Impact Mass Spectrum (EI-MS) was recorded by a Finnegan MAT95XL-T mass spectrometer operating at $70 \mathrm{eV}$ ionizing energy. Microanalyses were carried out on Perkin Elmer 2400 LS Series CHNS/O analyzer. FT-IR data were acquired on Perkin Elmer 2000-FTIR spectrophotometer in the frequency range of $4000-400 \mathrm{~cm}^{-1}$ with samples embedded in $\mathrm{KBr}$ discs. ${ }^{1} \mathrm{H}$ and ${ }^{13} \mathrm{C}$ NMR spectra were recorded in $\mathrm{CDCl}_{3}$ by utilizing JEOL $400 \mathrm{MHz}$ NMR Spectrometer with TMS as internal standard. The phase transition temperatures were measured by Mettler Toledo DSC823 Differential Scanning Calorimeter (DSC) at a scanning rate of $10^{\circ} \mathrm{C} \mathrm{min}^{-1}$.

Synthesis of Schiff bases: The title compounds are prepared according to the synthetic route in Scheme 1.

\section{RESULTS}

Spectral characteristics of Schiff bases 1-5 were studied by using mass spectrometric and spectroscopic methods. The results are presented in Table 1-3. The phase transition temperatures and their associated enthalpy obtained from DSC analysis over heating and cooling cycles are tabulated in Table 1. Representative DSC thermogram of Schiff base 5 is shown in Fig. 2.

\begin{tabular}{lll}
\hline$\delta /$ ppm & Splitting & Type of proton \\
\hline 0.89 & $\mathrm{t}$ & $\mathrm{CH}_{3}$ \\
$1.29-1.44$ & $\mathrm{~m}$ & $\mathrm{CH}_{3}\left(\mathrm{CH}_{2}\right)_{8^{-}}$ \\
1.77 & $\mathrm{qt}$ & $-\mathrm{C}_{2} \underline{\mathrm{CH}}_{2} \mathrm{COO}-$ \\
2.58 & $\mathrm{t}$ & $-\mathrm{C}_{2} \mathrm{COO}-$ \\
7.14 & $\mathrm{dd}$ & $\mathrm{Ar}-\mathrm{H}$ \\
7.26 & $\mathrm{dd}$ & $\mathrm{Ar}-\mathrm{H}$ \\
7.43 & $\mathrm{dd}$ & $\mathrm{Ar}-\mathrm{H}$ \\
8.30 & $\mathrm{dd}$ & $\mathrm{Ar}-\mathrm{H}$ \\
8.51 & $\mathrm{~s}$ & $\mathrm{CH}=\mathrm{N}$ \\
8.70 & $\mathrm{dd}$ & $\mathrm{Ar}-\mathrm{H}$ \\
9.02 & $\mathrm{~d}$ & $\mathrm{Ar}-\mathrm{H}$ \\
\hline
\end{tabular}

s: Singlet, d: Doublet; t: Triplet; m: Multiplet; qt: Quintet; dd: Double of doublets

\begin{tabular}{ll} 
Table $3:{ }^{13} \mathrm{C}$ NMR data of Schiff base 5 & \\
\hline$\delta / \mathrm{ppm}$ & Type of carbon \\
\hline 172.8 & $\mathrm{COO}$ \\
157.6 & $\mathrm{CH}=\mathrm{N}$ \\
$152.5,151.4,149.8$, & $\mathrm{Ar}-\mathrm{C}$ \\
$149.3,135.3,132.1$, & \\
$124.2,122.7,122.2$ & \\
34.8 & $-\mathrm{CH}_{2} \mathrm{COO}-$ \\
25.3 & $-\mathrm{CH}_{2} \mathrm{CH}_{2} \mathrm{COO}-$ \\
$32.3,30.0,29.9$, & $\mathrm{CH}_{3}\left(\mathrm{CH}_{2}\right)_{8^{-}}$ \\
$29.7,29.6,29.5$, & \\
$26.0,23.1$ & \\
14.5 & $\mathrm{CH}_{3}$ \\
\hline
\end{tabular}

Table 4: Transition temperatures and associated enthalpies of Schiff bases 2-5 upon heating and cooling

\begin{tabular}{ll}
\hline Schiff base & $\begin{array}{l}\text { Transition temperatures, } \\
{ }^{\circ} \mathrm{C}\left(\Delta \mathrm{H}, \mathrm{kJmol}^{-1}\right)\end{array}$ \\
\hline 2 & $\mathrm{Cr} 81.3(27.2) \mathrm{I}$ \\
& $\mathrm{I} 69.6(25.9) \mathrm{Cr}$ \\
& $\mathrm{Cr} 84.8(40.3) \mathrm{I}$ \\
4 & $\mathrm{I} 70.7(41.4) \mathrm{Cr}$ \\
5 & $\mathrm{Cr} 93.6(31.2) \mathrm{I}$ \\
5 & $\mathrm{I} 80.6(33.1) \mathrm{Cr}$ \\
& $\mathrm{Cr} 89.1(52.6) \mathrm{I}$ \\
& I $75.2(55.3) \mathrm{Cr}$ \\
\hline
\end{tabular}

The values in italic were taken during cooling cycle. Cr: Crystal; I: Isotropic liquid

\section{DISCUSSION}

Mass spectral studies: In the EIMS spectrum of Schiff base 5 , the peak at $\mathrm{m} / \mathrm{z}=464$ was assigned to the molecular ion $\left(\mathrm{M}^{+}\right)$which is in accordance with the compound having a molecular formula $\mathrm{C}_{30} \mathrm{H}_{44} \mathrm{~N}_{2} \mathrm{O}_{2}$. 


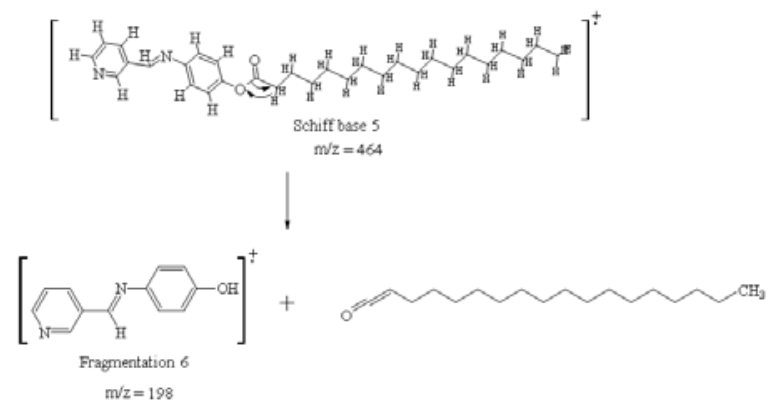

Fig. 1: Mass spectral fragmentation of Schiff base 5 leading to fragment ion 6 as the base peak

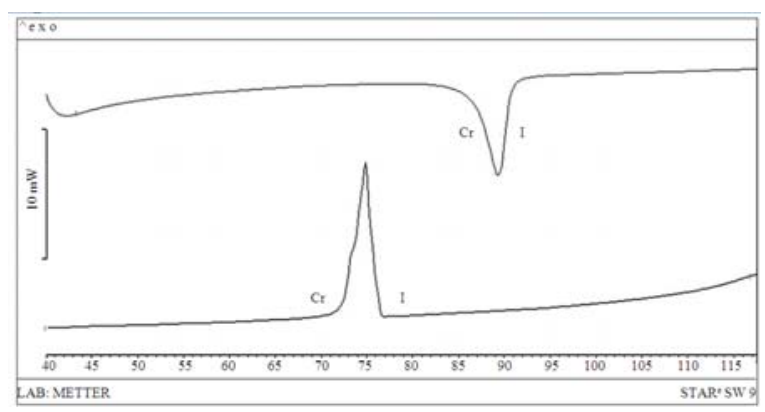

Fig. 2: DSC thermogram of Schiff base 5

Similarly, the peaks at 380,408 and 436 , attributed to the $\mathrm{M}^{+}$of Schiff bases 2, 3 and 4 confirmed those compounds to have a molecular formula $\mathrm{C}_{24} \mathrm{H}_{32} \mathrm{~N}_{2} \mathrm{O}_{2}$, $\mathrm{C}_{26} \mathrm{H}_{34} \mathrm{~N}_{2} \mathrm{O}_{2}$ and $\mathrm{C}_{28} \mathrm{H}_{40} \mathrm{~N}_{2} \mathrm{O}_{2}$ respectively. A difference in the value of $\mathrm{m} / \mathrm{z}$ by a margin of 28 units was observed when we proceed from compound 2-3, 3-4 and 4-5 due to the addition of an ethylene group $\left(\mathrm{CH}_{2} \mathrm{CH}_{2}\right)$ in each interval.

The diagnostic base peak at $\mathrm{m} / \mathrm{z}=198$ corresponding to fragment ion, 6 (Fig. 1), resulted from the McLafferty rearrangement in the parent ion of Schiff base 5 followed by the elimination of the neutral ketene molecule $\mathrm{CH}_{3}\left(\mathrm{CH}_{2}\right)_{15}-\mathrm{C}=\mathrm{C}=\mathrm{O}$ (Fig. 1), consistent with the loss of 266 mass units (Pavia et al., 2001). The proposed fragmentation was different from that reported for the unsubstituted salicylideneaniline and 1-hydroxy-2-naphthylidene-4'-subsituted-aniline of which either the $\mathrm{M}^{+}$or $(\mathrm{M}-1)^{+}$peak was the base peak for these compounds (Salman and Kamounah, 2002). The presence of the long alkyl chain favored the proposed fragmentation. The similar feature $[\mathrm{m} / \mathrm{z}=198$ $(100 \%)$ ] was observed in the EIMS spectra of Schiff bases 2,3 and 4 .

The EIMS spectra of Schiff bases 2, 3, 4 and 5 share a common feature, the diagnostic base peak being at $\mathrm{m} / \mathrm{z}=198$. This fragment ion, 6 (Fig. 1), resulted from the McLafferty rearrangement in the parent ion of Schiff bases 2-5 followed by the subsequent loss of the neutral ketene molecule $\mathrm{R}-\mathrm{C}=\mathrm{C}=\mathrm{O}\left[\mathrm{CH}_{3}\left(\mathrm{CH}_{2}\right)_{\mathrm{n}}\right.$, $\mathrm{n}=9,11,13$ and 15] as reported for benzyl esters (Pavia et al., 2001). As representative illustration, Fig. 1 shows the fragmentation of Schiff base 5 leading to fragment ion 6 as the base peak. The proposed fragmentation has been found to be different from that reported for the unsubstituted salicylideneaniline and 1hydroxy-2-naphthylidene-4'-subsituted-aniline of which either the $\mathrm{M}^{+}$or $(\mathrm{M}-1)^{+}$peak was the base peak for these compounds (Salman and Kamounah, 2002). This is due to the presence of long alkyl ester structure in the current Schiff bases 2-5 which is favorable to undergo Mclafferty rearrangement (Pavia et al., 2001).

Infrared spectral studies: Evidence which supports the fact that the title compounds were well isolated were indicated by the absence of the terminal hydroxyl group $(\mathrm{OH})$ which was originally attached to the para position of the aniline fragment and now has been substituted by $\mathrm{R}$, where $\mathrm{R}=\mathrm{C}_{\mathrm{n}-1} \mathrm{H}_{2 \mathrm{n}-1} \mathrm{COO}$ and $\mathrm{n}=12$, 14,16 and 18, respectively. The presence of the alkyl groups was confirmed by the occurrence of the absorption bands within the frequency range 2848$2953 \mathrm{~cm}^{-1}$. The intense peaks observed around 1754$1755 \mathrm{~cm}^{-1}$ in the IR spectra of the title compounds substantiated the presence of the $\mathrm{C}=\mathrm{O}$ group in the ester bond located between the aniline fragment and the aliphatic chain (Scheme 1). The absorption bands assignable to the stretching of the $\mathrm{C}=\mathrm{N}$ bond in Schiff bases 2-5 were observed at $1626 \mathrm{~cm}^{-1}$ and these values conform with those reported for para substituted 2-hydroxy-3-methoxybenzalideneanilines (Yeap et al., 2003).

NMR spectral studies: In ${ }^{1} \mathrm{H}$ NMR spectrum of Schiff base 5, two triplets were observed at $\delta=0.89$ and $2.58 \mathrm{ppm}$, which can be ascribed to the methyl and methylene protons $\left(-\mathrm{CH}_{2} \mathrm{COO}-\mathrm{Ar}\right)$. The chemical shifts at $\delta=1.23-1.45 \mathrm{ppm}$ can be assigned to methylene protons of long alkyl chain $\left\{-\left(\mathrm{CH}_{2}\right)_{14}\right\}$. The doublet and double doublet signals were detected at $\delta=7.13,7.25,7.41,8.28,8.71$ and $9.01 \mathrm{ppm}$ can be assigned to eight aromatic protons. A singlet was observed at $\delta=8.50 \mathrm{ppm}$ is due to proton of imine linking group (Ha et al., 2009). The molecular structure of Schiff base 5 was further verified by using ${ }^{13} \mathrm{C}$ NMR spectroscopy. A peak at $\delta=14.5 \mathrm{ppm}$ is attributed to the methyl carbon and peaks at $\delta=23.1$ $34.8 \mathrm{ppm}$ is contributed by the methylene carbons of long alkyl chain. Peaks at $\delta=122.2-152.5 \mathrm{ppm}$ is assigned to eleven aromatic carbons in Schiff base 5 . 


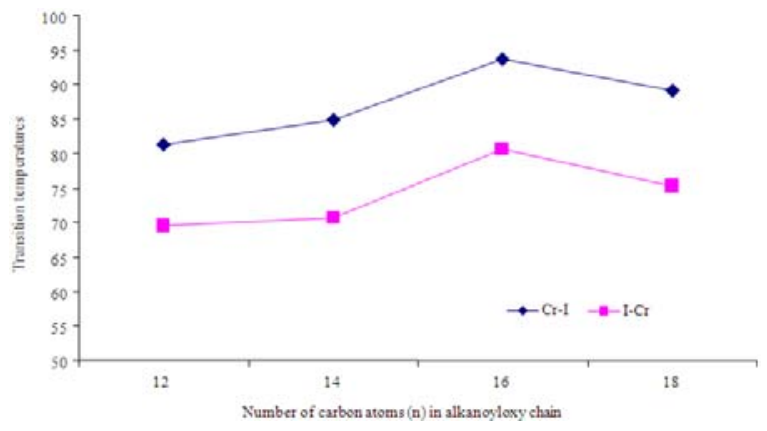

Fig. 3: Plot of transition temperatures versus the number of carbons (n) in the alkanoyloxy chain of Schiff bases 2-5

The peak at $\delta=157.6 \mathrm{ppm}$ due to existence of azomethine carbon. The most downfield peak in the spectrum, $\delta=172.7 \mathrm{ppm}$, is ascribed to carbon of ester group.

Phase transition behaviors and optical texture studies: The DSC thermograms for all compounds during heating cycle show only one peak that can be ascribed to direct isotropization process (Cr-to-I). Under polarizing optical microscope studies, crystal phase texture was observed to change to dark region isotropic during heating run. No liquid crystal texture was observed during cooling process. It is because the pyridine core at the terminal position has suppressed the formation of mesophase.

A further examination of DSC data also illustrates the evolution of the Cr-I transition with the lengthening of terminal chains. A plot of the melting and recrystallization temperatures against the number of carbons in the alkanoyloxy chain during the heating and cooling cycles is shown in Fig. 3. The melting temperatures for Schiff bases 2-4 increases as the alkyl chain of $\mathrm{C}_{\mathrm{n}-1} \mathrm{H}_{2 \mathrm{n}-1} \mathrm{COO}$ - elongates in the range of $\mathrm{n}=12-16$. This observation could be attributed to the increase of van der Waals attraction when the alkyl chains of the title compounds $\left(\mathrm{C}_{\mathrm{n}-1} \mathrm{H}_{2 \mathrm{n}-1} \mathrm{COO}-\right)$ varied from 12-14 and 16. However, the melting temperature of Schiff base 5 is found to be lower than Schiff base 4 . The lowering of the melting temperature in Schiff base 5 wherein $n=18$ could probably be due to the repulsive (steric) forces leading to larger intermolecular distance. One of the reasons that can explain the repulsion among the molecules in Schiff base 5 is the probable deviation from the linearity of the terminal alkanoyloxy chain. Although the molecular structure for compounds 2-4 may be fully stretched, the long molecular axis of
Schiff base 5 could be distorted from linearity, which entails molecular packing as reported for the azomethines containing terminal cycloalkyl ring systems (Byron et al., 1995). The melting trend as discussed above (Fig. 3) is found to conform with the trend reported for 1-phenyl-3-(4alkylcarbonyloxyphenyl)-2-propen-1-one (Yeap et al., 2005).

\section{CONCLUSION}

Spectral, optical and thermal behaviors of a homologous series of Schiff base ester with pyridine core were studies. Melting and recrystallization points were greatly influenced by the changes of alkyl chain length. Pyridine core at terminal position was found able to inhibit formation of liquid crystal phase in Schiff bases.

\section{ACKNOWLEDGEMENT}

The researcher (S.T. Ha) would like to thank University Tunku Abdul Rahman (UTAR) for the research facilities and financial support through UTAR Research Fund (Vote No. 6200/H02).

\section{REFERENCES}

Byron, D.J., A.S. Matharu, M. Rees and R.C. Wilson, 1995. Properties of the liquid crystals formed by certain azomethines containing terminal cycloalkyl ring systems. Mol. Cryst. Liquid Cryst., 258: 217-228. DOI: $10.1080 / 10587259508034562$

Ha, S.T., L.K. Ong, S.T. Ong, G.Y. Yeap and J.P.W. Wong et al., 2009. Synthesis and mesomorphic properties of new Schiff base esters with different alkyl chains. Chin. Chem. Lett., 20: 767-770. DOI: 10.1016/j.cclet.2009.01.011

Hadjoudis, E., M. Vittorakis and I. Moustakali-Mavridis, 1987. Photochromism and thermochromism of Schiff bases in the solid state and in rigid glasses. Tetrahedron, 43: 1345-1360. DOI: 10.1016/S00404020(01)90255-8

Pavia, D.L., G.M. Lampman and G.S. Kriz, 2001. Introduction to Spectroscopy: A Guide for Students of Organic Chemistry. 3rd Edn., Brooks/Cole Thomson Learning, Singapore, ISBN: 0-03031961-7, pp: 649.

Salman, S.R. and F.S. Kamounah, 2002. Mass spectral study of tautomerism in some 1-hydroxy-2naphthaldehyde schiff bases. Spectrosc. Lett., 35: 327-335. DOI: 10.1081/SL-120005669 
Yeap, G.Y., S.T. Ha, N. Ishizawa, K. Suda, P.L. Boey and W.A.K. Mahmood, 2003. Synthesis, crystal structure and spectroscopic study of para substituted 2-hydroxy-3methoxybenzalideneanilines. J. Mol. Struct., 658: 87-99. DOI: 10.1016/S0022-2860(03)00453-8

Yeap, G.Y., S.T. Ha, P.L. Lim, P.L. Boey and W.A.K. Mahmood et al., 2004. Synthesis and mesomorphic properties of Schiff base esters orthohydroxy-para-alkyloxybenzylidene-para-substituted anilines. Mol. Cryst. Liquid Cryst., 423: 73-84. DOI: $10.1080 / 15421400490494508$

Yeap, G.Y., I. Susanti, B.S. Teoh, W.A.K. Mahmood and W.T.A. Harrison, 2005. Synthesis and phase transition in new chalcone derivatives: Crystal structure of 1-phenyl-3-(4undecylcarbonyloxyphenyl)-2-propen-1-one. Mol. Cryst. Liquid Cryst., 442: 133-146. DOI: $10.1080 / 154214090964753$
Yeap, G.Y., S.T. Ha, P.L. Lim, P.L. Boey and M.M. Ito et al., 2006a. Nematic and smectic A phases in ortho-hydroxy-parahexadecanoyloxybenzylidene-para-substituted anilines. Mol. Cryst. Liquid Cryst., 452: 63-72. DOI: 10.1080/15421400500377750

Yeap, G.Y., S.T. Ha, P.L. Boey, W.A.K. Mahmood and M.M. Ito et al., 2006b. Synthesis and characterization of some new mesogenic schiff base esters N-[4-(4-nhexadecanoyloxybenzoyloxy) benzylidene]-4substitued anilines. Mol. Cryst. Liquid Cryst., 452: 73-90. DOI: 10.1080/15421400500382156

Yeap, G.Y., S.T. Ha, P.L. Lim, P.L. Boey and M.M. Ito et al., 2006c. Synthesis, physical and mesomorphic properties of schiff base esters containing ortho-,meta- and para-substituents in benzylidene-4'-alkanoyloxyanilines. Liquid Cryst., 33: 205-211. DOI: 10.1080/02678290500450584 